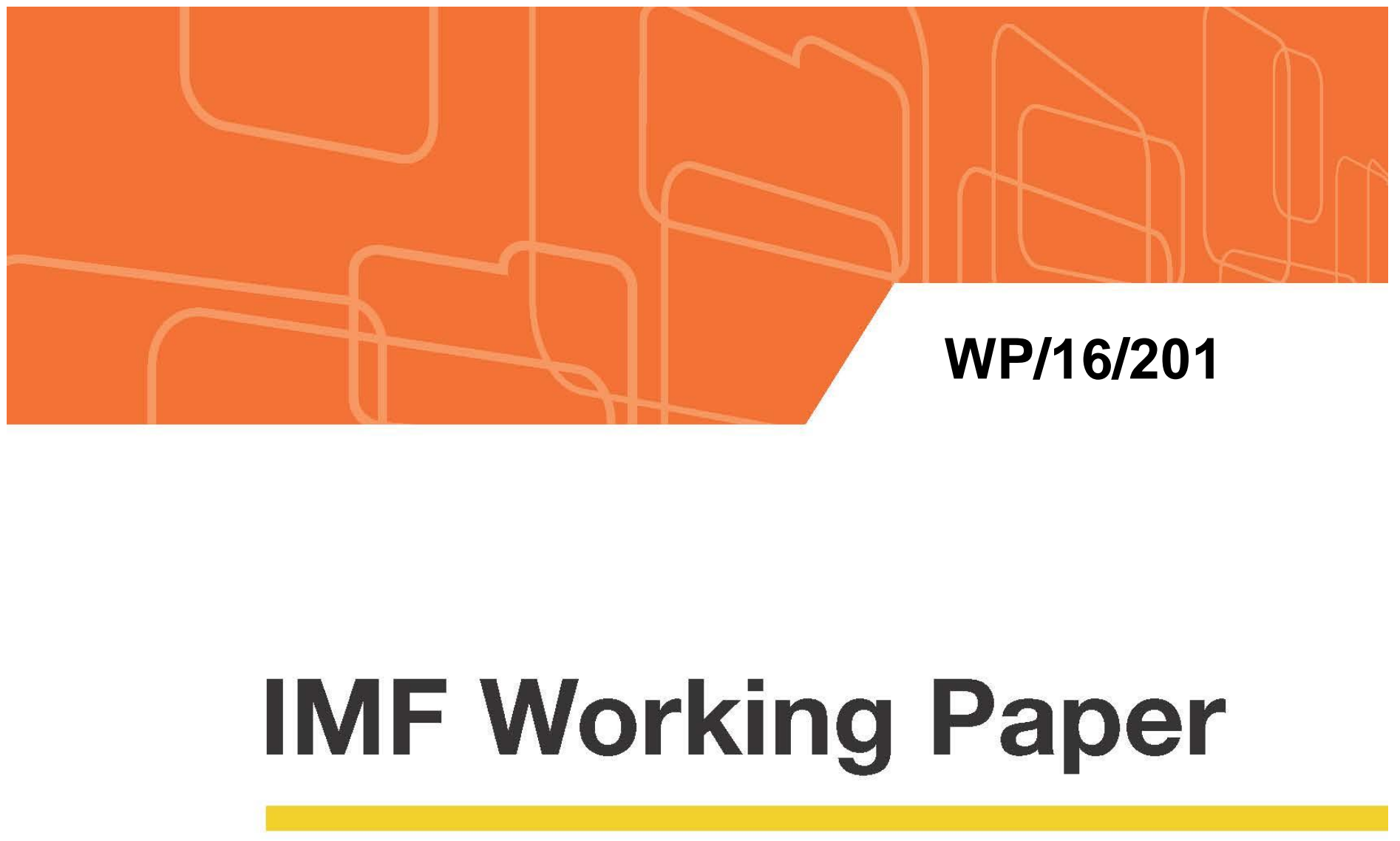

\title{
Estimating Potential Output in Chile: A Multivariate Filter for Mining and Non-Mining Sectors
}

By Patrick Blagrave and Marika Santoro 


\title{
IMF Working Paper
}

\author{
Research Department
}

\section{Estimating Potential Output in Chile: A Multivariate Filter for Mining and Non-Mining Sectors}

\section{Prepared by Patrick Blagrave and Marika Santoro ${ }^{1}$}

Authorized for distribution by Stephan Danninger

October 2016

\section{IMF Working Papers describe research in progress by the author(s) and are published to elicit comments and to encourage debate. The views expressed in IMF Working Papers are those of the author(s) and do not necessarily represent the views of the IMF, its Executive Board, or IMF management.}

\begin{abstract}
Using a multivariate filter, we estimate potential growth rates in Chile's mining and non-mining sectors. Estimates for the mining sector incorporate information on copper prices, whereas estimates for non-mining reflect information on inflation and unemployment rates. To better understand the drivers of potential growth, we decompose estimates into capital, labor (adjusted for human-capital and hours worked), and total-factor productivity using a production-function. Our estimates of potential output in Chile suggest that an important part of the recent growth slowdown has been structural, with potential-output growth slowing to $2 \frac{1}{2}$ percent in recent years, although it plausibly could be higher in the medium-term.

JEL Classification Numbers: C51, E31, E52

Keywords: Macroeconomic Modeling, Potential Output, Production Function

Author's E-Mail Address: PBlagrave@imf.org, MSantoro@imf.org
\end{abstract}

\footnotetext{
${ }^{1}$ The views expressed in this paper are those of the authors and do not necessarily represent those of the IMF or IMF policy. The authors would like to thank Elias Albagli, Yan Carrière-Swallow, Stephan Danninger, Jorge Fornero, Markus Kirchner, Alberto Naudon, María Paz González, and Jorge Roldos for helpful comments. Ehab Tawfik provided outstanding research assistance. All errors and omissions are our own.
} 
I. Introduction

II. Recent Developments in Chile ___ 4

III. Estimating Potential Output: Methodology __ 5

A. Potential output in the non-mining sector

B. Potential output in the mining sector___ 8

IV. Estimating Potential Output: Results _ 10

A. Estimates from the multivariate filter

B. Decomposition of estimates using a production-function approach ___ 14

B. What are the factors behind weaker growth in capital accumulation? 17

C. What explains the deceleration in TFP growth?__ 19

D. What is behind low labor-input growth?_ 20

V. Conclusion _ 21

VI. References

VII. Appendix _ 26

A. Estimation priors, posteriors, and data sources _ 26

B. Uncertainty Inherent in Potential Output and Output Gap Estimates___ 28

C. Robustness Testing and Alternate Specifications ___ 29 


\section{INTRODUCTION}

In recent years Chile has experienced a sharp growth slowdown-from a peak of nearly 6 percent in 2011, to around 2 percent in 2014 and 2015-coinciding with the reversal of previous commodity (copper) price increases. Interestingly, the growth slowdown has been very broad-based, with growth in the mining sector — which represents only a small share of activity-faring no worse than that in other sectors.

The objective of this paper is to assess whether the slowdown in the different sectors is cyclical, or structural in nature. With this in mind, we estimate potential output following the multivariate filtering methodology (MVF) applied in Blagrave and others (2015), IMF (2015), Benes and others (2010), among other recent studies. The definition of potential output used in this paper - that is, the level of output that can be achieved without excessive inflation or labor-market imbalances - is particularly prevalent among monetary policy makers, as it allows them to communicate their policy stance in the context of the short-run tradeoff between output and inflation. This concept differs from that of medium-term trend output - a notion that will be explored further in a companion paper (Blagrave and Santoro, 2016).

Our approach to estimating potential output departs from the aforementioned studies by extending the MVF approach to study the mining and non-mining sectors of the Chilean economy separately. This distinction is important because these two sectors differ in terms of their production technologies and processes, as well as their linkages to the domestic economy, in a non-trivial way. In addition, using a production-function approach, we highlight that different structural factors are driving potential growth in these two types of sectors.

The application of the MVF to the non-mining sector is standard fare-we add information on inflation and unemployment rates to help condition the estimates of the output gap and potential output. In the mining sector, we adopt a simpler, novel approach which excludes inflation and unemployment rates, but the estimates of potential growth are augmented with information on copper prices to reflect the idea that capacity decisions are related to durable changes in those prices (Harchaoui and Lasserre (2001), among others).

Estimates for the non-mining sector show a significant deterioration in potential output growth in recent years, coinciding with an estimated output gap which is small at the end of the sample. In the mining sector, estimates of potential growth are highly correlated with trend copper prices, suggesting a run-up in mining-sector potential in recent yearsfollowing an extended period of low or even negative potential growth - which is now unwinding as prices have fallen. We estimate that there is considerable slack in the mining sector, implying that productive resources should be shifted elsewhere. In all, the estimates 
show that potential growth for the Chilean economy in 2015-16 has slowed significantlyalthough subject to uncertainty, our point estimate of $2 \frac{1}{2}$ is roughly half of what it was in 2011. And, the non-mining sector accounts for the bulk of the slowdown. ${ }^{2}$

To gain a better understanding of the drivers of potential output, we conduct a growthaccounting exercise using a standard Cobb-Douglas production function. For the non-mining sectors, this exercise highlights an important role for weaker capital accumulation in driving the slowdown in potential growth (explaining about $1 / 2$ the estimated slowdown), with labor inputs and total-factor productivity (TFP) growth slowdowns explaining the rest (20 and 30 percent of the slowdown, respectively). These results stand somewhat in contrast to the findings in IMF (2015), which suggest that the potential-growth slowdown observed in many EMs is predominantly explained by weaker TFP growth. For the mining sector, estimates of potential growth are low or even negative for much of the sample period, due to a long period of decreasing TFP, related to a gradual deterioration of ore grade at copper mines as the most profitable deposits are extracted first. This has required a continuous (but not offsetting) increase in capital accumulation.

When interpreting these findings several factors need to be taken into consideration. First, there is substantial uncertainty about point estimates of potential growth but less so about its change - there has been a clear deceleration of potential growth in recent years. ${ }^{3}$ Second, as mentioned earlier, the concept of potential growth estimated in the present paper is a shortrun concept and is time-varying — as such, the current estimate of $2 \frac{1}{2}$ percent should not be understood as a medium or long-term value. Current estimates of potential are affected by several developments, including a drawn-out adjustment process to the copper price decline, productivity changes related to a slowdown in investment, and demographic effects. Finally, Chile's growth slowdown mirrors trends in other countries. Many emerging and developed economies have experienced a similar decline in potential growth (IMF 2015). While the growth slowdown in Chile may partly be related to convergence - the effect that growth slows as per-capita income rises - there are other factors at play. Headwinds from population aging (Blagrave and Santoro 2016) and also structural bottlenecks, such as a large infrastructure gap (Santoro 2015), are other reasons that need to be reckoned with.

The remainder of the paper begins with a brief review of stylized facts about the recent evolution of the Chilean economy. Following that discussion, the third section presents the MVF for both the mining and non-mining sectors; estimates of potential and the output gap

\footnotetext{
${ }^{2}$ Determining whether weakness in the non-mining sector is due to shocks to the mining sector, or domestic/external conditions more broadly, is beyond the scope of this paper.

${ }^{3}$ The accuracy of the point estimates of potential growth depends on how well economic activity, labor market tightness, and other variables are measured.
} 
are presented in section four, including a production-function potential-growth accounting exercise. Section five concludes and raises questions for future research.

\section{RECENT DEVELOPMENTS IN CHILE}

After experiencing relatively strong GDP growth for much of the past decade - averaging 4.5 percent between 2000 and 2013 - growth in Chile has deteriorated recently, averaging only 2 percent since then. One obvious contributing factor, given the importance of coppermining exports in Chile, has been the deterioration in copper prices, which were holding above or near $\$ 3.50$ per pound for much of the past decade (with the notable, but short-lived, exception of the global financial crisis). Since late 2011, copper prices have fallen significantly, and are now at just over $\$ 2.00$ per pound. Lower copper prices have been associated with lower growth in the mining sector-falling from 4.7 percent in 2012-2013 to an average of 1.4 percent in 2014-15-though activity in the sector is highly volatile.

Ultimately, the mining sector in Chile accounts, however, for a relatively small share of total activity — on average 13 percent of value added between 2011 and 2015. As such, in order for economy-wide GDP growth to have slowed so markedly, other sectors must have experienced significantly weaker growth as well. Indeed, during 2014-15 average growth rates in other sectors have slowed considerably.

Delving further into the linkages between these different sectors and the domestic economy, the mining sector is predominantly subject to external shocks. In particular, we note that the mining sector comprises about 60 percent of total goods exports in Chile, with almost all its production being exported. In addition, on the demand side the mining sector sources the bulk of its capital goods

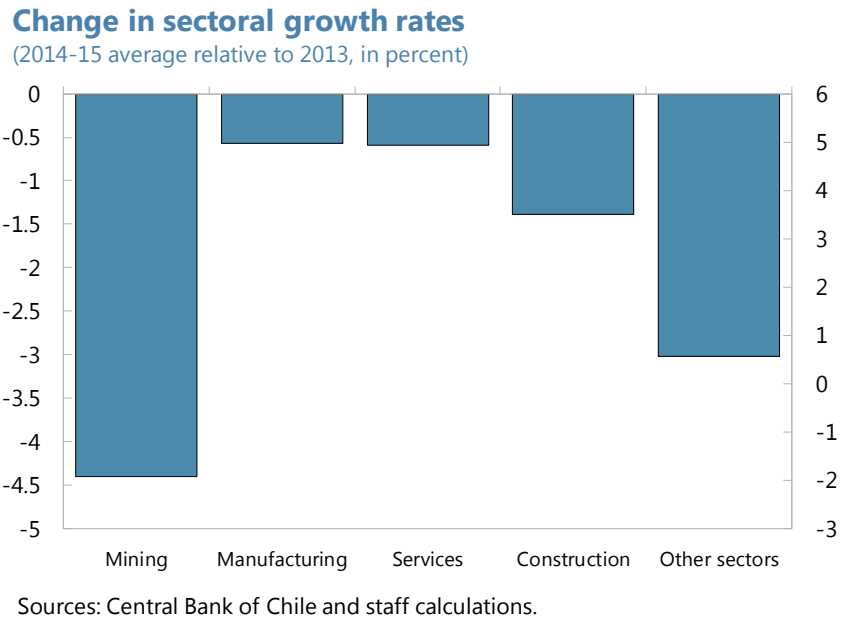
externally, with over 60 percent of machinery and equipment being imported. Combined, these considerations suggest a need for separate treatment of the sector, and a treatment which relates activity less to domestic conditions than is the case for other, non-mining sectors of the economy.

With this background information in mind, we turn to an examination of the degree to which the recent slowdown has been cyclical and to which degree it has been structural. 


\section{Estimating Potential OUtPut: Methodology}

Recent efforts to estimate potential output in a host of different countries have emphasized the Okun (1962) definition of potential output, wherein economic slack is related to slack in the labor market and inflationary pressures. The use of a multivariate filter allows practitioners to impose some economic theory on the results, and offers numerous other benefits relative to a naïve statistical filtration of the data. ${ }^{4}$

Many practitioners, including the U.S. Congressional Budget Office (CBO, 2001), choose to estimate potential output separately for different sectors of the economy, particularly those with different production methods. In Chile, the production process in the mining sector differs markedly from that of the rest of the economy, employing a much higher share of capital than production elsewhere, and responding much more to internationally determined variables, such as the price of copper, international demand and imported (capital) goods prices. ${ }^{5}$ For this reason, we estimate potential output separately in the mining and non-mining sectors.

\section{A. Potential output in the non-mining sector}

The methodology used to estimate potential output in the non-mining sector is relatively simple, requiring annual data on just three observable variables: real GDP growth, CPI inflation, and the unemployment rate. The equations which relate these three observable variables to the latent variables in the model are presented below. Parameter values and the variances of shock terms for these equations are estimated using Bayesian estimation techniques. ${ }^{6}$

In the model, the output gap is defined as the deviation of real GDP, in log terms $(Y)$, from its potential level $(\bar{Y})$ :

$$
y_{t}=Y_{t}-\overline{Y_{t}}
$$

\footnotetext{
${ }^{4}$ For a more extensive discussion on other techniques used to estimate potential output, and the relative strengths of the MVF approach taken here, see Blagrave and others (2015).

${ }^{5}$ ACTU (2013) calculates the labor share of income for the whole economy, and non-mining sectors. The difference between those two values can be used to impute the labor share in mining (in Australia) which is around 0.15-0.2.

${ }^{6}$ Parameter estimates and some further discussion on the selection of priors are provided in an appendix (section A).
} 
The stochastic process for output (real GDP) is comprised of three equations, and subject to three types of shocks:

$$
\begin{aligned}
& \bar{Y}_{t}=\bar{Y}_{t-1}+G_{t}+\varepsilon_{t}^{\bar{Y}} \\
& G_{t}=\theta G^{S S}+(1-\theta) G_{t-1}+\varepsilon_{t}^{G} \\
& y_{t}=\phi y_{t-1}+\varepsilon_{t}^{y}
\end{aligned}
$$

The level of potential output $\left(\bar{Y}_{t}\right)$ evolves according to potential growth $\left(G_{t}\right)$ and a levelshock term $\left(\varepsilon_{t}^{\bar{Y}}\right)$. Potential growth is also subject to shocks $\left(\varepsilon_{t}^{G}\right)$, with their impact fading gradually according to the parameter $\theta$ (with lower values entailing a slower adjustment back to the steady-state growth rate following a shock). ${ }^{7}$ Finally, the output-gap is also subject to shocks $\left(\varepsilon_{t}^{y}\right)$-in effect, demand shocks. The role of each shock term is expressed graphically below:

\section{Shocks to the level and growth rate of potential output, and the output gap}

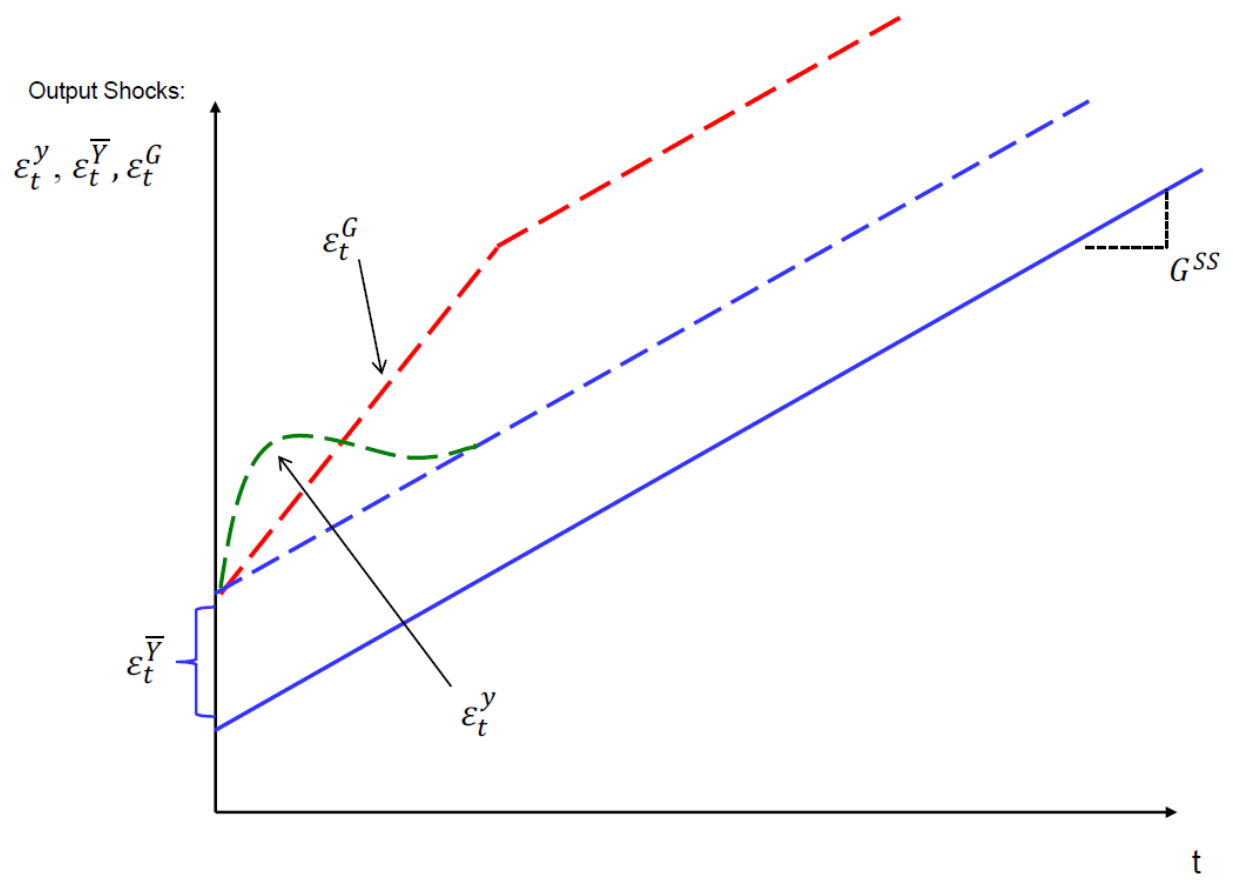

\footnotetext{
${ }^{7}$ The notion of steady-state growth $\left(G^{S S}\right)$ in this model is not derived from theory, and is simply calibrated in order to provide a sensible starting point for the filter at the beginning of the sample - estimates of potential growth $\left(G_{t}\right)$ will, in practice, deviate from this value frequently.
} 
All else equal, output would be expected to follow its steady-state path, which is shown above by the solid blue line (which has a slope of $G^{S S}$ ). However, shocks to: the level of potential $\left(\varepsilon_{t}^{\bar{Y}}\right)$; the growth rate of potential $\left(\varepsilon_{t}^{G}\right)$; or the output gap $\left(\varepsilon_{t}^{y}\right)$, can cause output to deviate from this initial steady-state path over time. As shown by the dashed blue line, a shock to the level of potential output in any given period will cause output to be permanently higher (or lower) than its initial steady-state path. Similarly, shocks to the growth rate of potential, illustrated by the dashed red line, can cause the growth rate of output to be higher temporarily, before ultimately slowing back to the steady-state growth rate (note that this would still entail a higher level of output). And, finally, shocks to the output gap would cause only a temporary deviation of output from potential, as shown by the dashed green line.

In order to help identify the three aforementioned output-shock terms, a Phillips Curve equation for inflation is added, which links the evolution of the output gap (an unobservable variable) to observable data on headline inflation according to the process: ${ }^{8}$

$$
\pi_{t}=\lambda \pi_{t+1}+(1-\lambda) \pi_{t-1}+\beta y_{t}+\varepsilon_{t}^{\pi}
$$

Finally, equations describing the evolution of unemployment are included to provide further identifying information for the estimation of the output gap:

$$
\begin{aligned}
& \bar{U}_{t}=\left(\tau_{4} \bar{U}^{s s}+\left(1-\tau_{4}\right) \bar{U}_{t-1}\right)+g \bar{U}_{t}+\varepsilon_{t}^{\bar{U}} \\
& g \bar{U}_{t}=\left(1-\tau_{3}\right) g \bar{U}_{t-1}+\varepsilon_{t}^{g \bar{U}} \\
& u_{t}=\tau_{2} u_{t-1}+\tau_{1} y_{t}+\varepsilon_{t}^{u} \\
& u_{t}=\bar{U}_{t}-U_{t}
\end{aligned}
$$

\footnotetext{
${ }^{8}$ Our baseline specification relies on headline CPI inflation, but is robust to the use of core inflation in its place. In the case of Chile, the relationship between economic slack and inflation (the parameter $\beta$ ) is estimated to be quite small, presumably in part due to credible and consistent monetary policy which has kept inflation expectations well anchored. This is in line with Perez Ruiz (2016). In addition, we opt not to add additional terms to the Phillips curve (such changes in the exchange rate) since this information is not expected to materially change the estimates of the output gap and potential output (it would reduce the error term and improve fit, but not affect the estimate of the parameter, $\beta$, which is what matters for the estimation of the output gap and potential output). This is demonstrated in an appendix (section $\mathrm{C}$ ).
} 
Here, $\bar{U}_{t}$ is the equilibrium value of the unemployment rate (the NAIRU), which is time varying, and subject to shocks $\left(\varepsilon_{t}^{\bar{U}}\right)$ and also variation in the trend $\left(g \bar{U}_{t}\right)$, which is itself also subject to shocks $\left(\varepsilon_{t}^{g \bar{U}}\right)$ - this specification allows for persistent deviations of the NAIRU from its steady-state value. Most importantly, we specify an Okun's law relationship wherein the gap between actual unemployment $\left(U_{t}\right)$ and its equilibrium process (given by $u_{t}$ ) is a function of the amount of slack in the economy $\left(y_{t}\right)$.

Equations 1-9 comprise the core of the model for potential output in the non-mining sectors. In addition, data on growth and inflation expectations are added, in part to help identify shocks, but mostly to improve the accuracy of estimates at the end of the sample period:

$$
\begin{aligned}
& \pi_{t+j}^{C}=\pi_{t+j}+\varepsilon_{t+j}^{\pi^{C}}, \mathrm{j}=0,1 \\
& G R O W T H_{t+j}^{C}=G R O W T H_{t+j}+\varepsilon_{t+j}^{G R O W T H^{C}}, \mathrm{j}=0, \ldots, 5
\end{aligned}
$$

For real GDP growth (GROWTH) the model is augmented with forecasts from consensus economics for the five years following the end of the sample period. For inflation, consensus economics forecasts are added for one year following the end of the sample period. These equations relate the model-consistent forward expectation for growth and inflation $\left(\pi_{t+j}\right.$ and $G R O W T H_{t+j}$ ) to observable data on how consensus forecasters expect these variables to evolve over various horizons (one to five years ahead) at any given time $\left(G R O W T H_{t+j}^{C}\right){ }^{9}$

\section{B. Potential output in the mining sector}

The structure of the MVF used to estimate potential output in the mining sector is broadly similar to what was presented in the previous section, with a few simplifications and one alteration. In particular, the first block of equations is as follows:

\footnotetext{
9 The 'strength' of the relationship between the data on consensus and the model's forward expectation is determined by the standard deviation of the error terms $\left(\varepsilon_{t+j}^{\pi^{C}}\right.$ and $\left.\varepsilon_{t+j}^{G R O W T H^{C}}\right)$. In practice, the estimated variance of these terms allows consensus data to influence, but not completely override the model's expectations, particularly at the end of the sample period. The impact of this information on the historical estimates of potential and the output gap is modest - at the end of the sample, this information plays a more important role.
} 


$$
\begin{aligned}
& y_{t}^{M}=Y_{t}^{M}-\bar{Y}_{t}^{M} \\
& \overline{Y_{t}^{M}}=\overline{Y_{t-1}^{M}}+G_{t}^{M}+\varepsilon_{t}^{\overline{Y^{M}}} \\
& G_{t}^{M}=\theta^{M} G^{M_{S S}}+\left(1-\theta_{M}\right) G_{t-1}^{M}+\varepsilon_{t}^{G^{M}} \\
& y_{t}^{M}=\phi^{M} y_{t-1}^{M}+\varepsilon_{t}^{p}+\varepsilon_{t}^{y^{M}}
\end{aligned}
$$

Equations 12-14 are identical to equations 1-3, presented for the non-mining sector (though all variables and parameters take the superscript ' $M$ ' to denote that they belong to the mining sector). In equation 15 (the behavioral output-gap equation) we add the term $\varepsilon_{t}^{p}$ to link the evolution of the mining-sector output gap (and hence potential-output estimates) to the evolution of copper prices. This link between copper prices and mining-sector potential output is motivated by the idea that the degree to which price changes are judged to be persistent (or permanent) will drive investment and staffing (capacity-related) decisions in the mining sector, and hence matter for mining-sector potential output. This approach finds support in the work of Aslam and others (2016), who show that capital accumulation grows more strongly in commodity-producing countries during episodes of sustained terms-of-trade shocks (booms). The block of equations which describes the evolution of copper prices is as follows: ${ }^{10}$

$$
\begin{aligned}
& p_{t}=P_{t}-\overline{P_{t}} \\
& p_{t}=(1-\rho) p_{t-1}+\varepsilon_{t}^{p} \\
& \bar{P}_{t}=(1-\mu) \overline{P_{t-1}}+\bar{P}_{s s}+\varepsilon_{t}^{\bar{P}}
\end{aligned}
$$

These equations allow the filter to parse copper prices into movements due to cyclical and trend shocks. The copper-price gap $\left(p_{t}\right)$ is defined as the deviation of the actual price $\left(P_{t}\right)$ from its trend, or structural, component $\left(\overline{P_{t}}\right)$, and its dynamics are defined in equation 17. Trend copper prices are defined in equation 18, and this process is relatively slow moving, consistent with work by Wets and Rios (2015) who suggest that the 'stationary' or long-term regime in copper prices is slow moving.

\footnotetext{
${ }^{10}$ The concept of mining-sector potential output invoked here is a relatively short-run concept-it is the degree to which capacity to extract existing ore exists in the near-term. In the medium-to-long run, the potential output of the mining sector is theoretically given by the amount of ore available to be extracted and the optimal pace at which it should be extracted. According to Hotelling (1931) the optimal rate of extraction would be governed by the expected future price of copper, and time-preference (interest rate) considerations.
} 
The properties of this block of equations imply that temporary movements in copper prices will be interpreted by the multivariate filter as shocks to the copper-price gap $\left(\varepsilon_{t}^{p}\right)$, and hence will be translated into movements in the mining-sector output gap (through equation 15) with little or no change to mining-sector potential output growth. On the other hand, more persistent movements in copper prices will gradually be interpreted by the filter as representing trend copper-price movements, which will be assigned to trend shocks $\left(\varepsilon_{t}^{\bar{P}}\right)$ instead of copper-price gap shocks - the implication is that these would imply a change in mining-sector potential output.

Finally, relative to the setup for the non-mining sector, the MVF for the mining sector has been streamlined by eliminating conditioning information from inflation and unemployment rates (equations 5-9). Furthermore, we do not include information on consensus forecasts for mining-sector output as they are not available. To partially alleviate the end-of-sample problem we run the filter through a crude forecast of mining-sector GDP growth and copper prices (until 2017).

\section{Estimating Potential OUtPut: Results}

\section{A. Estimates from the multivariate filter}

Relative to the estimates from an HP filter, the MVF estimates of potential output growth are more flexible. This is mainly because the MVF assigns some variation in observed GDP to level shocks to potential output (the term $\varepsilon_{t}^{\bar{Y}}$ from equation 2) during periods of sharp declines in GDP growth - this allows potential output growth to be more a flexible process, which improves real-time accuracy of the estimates and also minimizes counter-intuitive revisions to historical estimates. ${ }^{11}$ In addition, this more rapid adjustment of potential output is consistent with the idea that the business cycle in emerging market economies tends to be driven, to an important degree, by shocks to potential output (Aguiar and Gopinath, 2007).

\section{A.1. MVF Estimation results: non-mining sectors}

Figure 1 displays estimated potential growth rates using a standard HP filter (dashed green line) and those obtained by using the MVF approach (solid blue line). Parameters' estimates are shown in Appendix A, Table A1. Data source and description are displayed in Table A2.

\footnotetext{
${ }^{11}$ A smoother process for potential growth implies that during sharp downturns (or upswings), potential growth must be revised in the period prior to the onset of the downturn (or upswing) in order for output-gap estimates to be plausible. For a more detailed discussion of the limitations of the HP filter as a tool to estimate potential output, and the stability of the MVF's estimates at the end of the sample, see Blagrave and others (2015).
} 
Estimates for the most recent period suggest that potential growth has slowed significantly, from about 5 percent in 2011 reaching a trough of around $2 \frac{1}{2} 2$ percent in 2015-16. There is considerable uncertainty surrounding these estimates, particularly at the end of the sample. To assess this uncertainty, we construct confidence bands around our estimates of potential growth by taking 1000 draws of all latent variables from the model using Monte Carlo methods. The resulting confidence bands suggest that potential growth in 2015-16 could be as low as 1.5 or as high as 3.5 percent (confidence level of 95 percent, see Appendix B). ${ }^{12}$ Taking these intervals into account, the estimates imply that the potential growth rate in 2015 was lower than that in 2010-12 at conventional statistical thresholds. The estimated slowdown in recent years is in line with the arguments of De Gregorio (2015), who reports that many emerging economies (EM) in Latin America are facing similar deteriorations in potential growth.

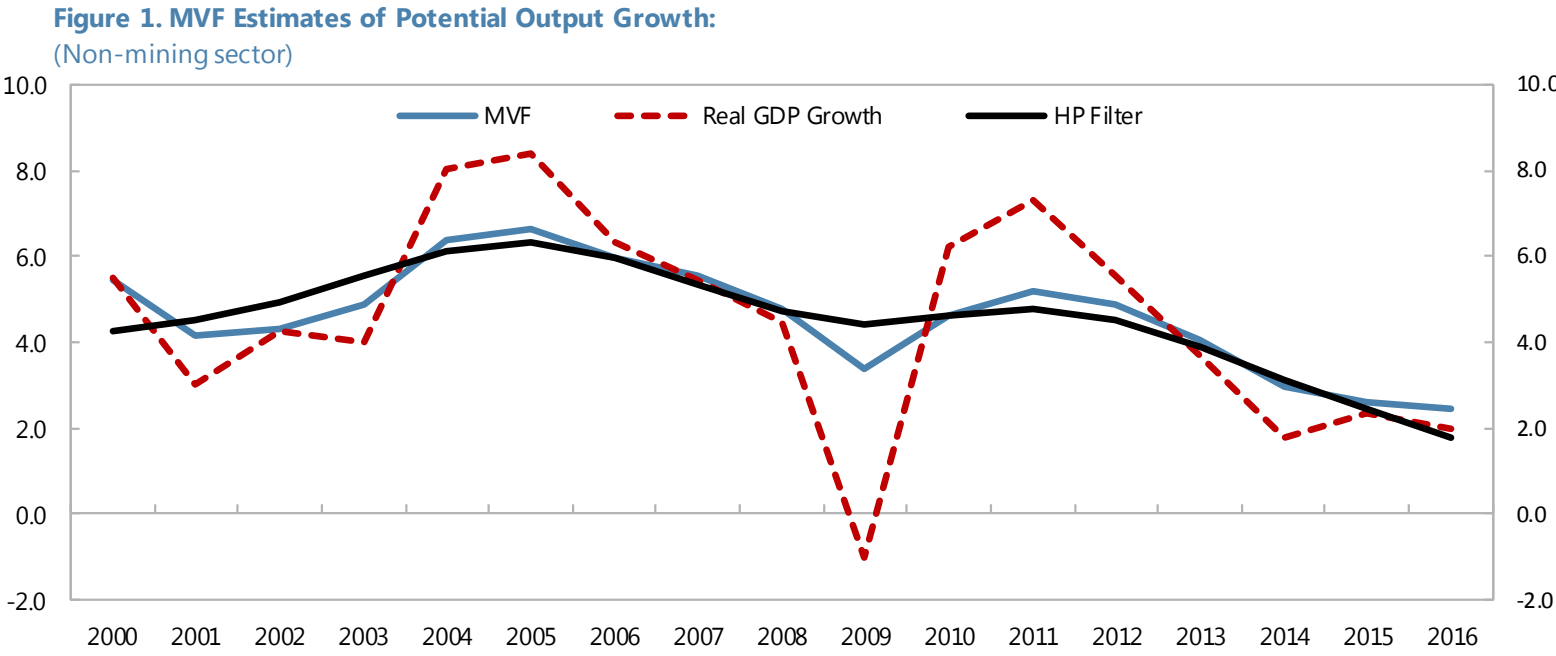

\footnotetext{
${ }^{12}$ These confidence bands measure the uncertainty inherent in the MVF's estimates of the latent variables and are presented in an appendix. They do not capture parameter or model uncertainty, which are broader concepts beyond the scope of this exercise.
} 
To put the decline of Chile's potential output growth in a broader context, Figures 2 and 3 show how its deterioration in recent years compares to those of other emerging market economies, as well as how its current estimated potential growth rate compares to those of other countries based on GDP-per-capita. ${ }^{13}$ Chile's decline stands out as large, but still consistent with the experiences of many other EMs over this period. Among countries with a similar income level, potential growth rates of between 2 and 3 percent are not particularly low and in line with expectations based on economic convergence. Indeed, IMF

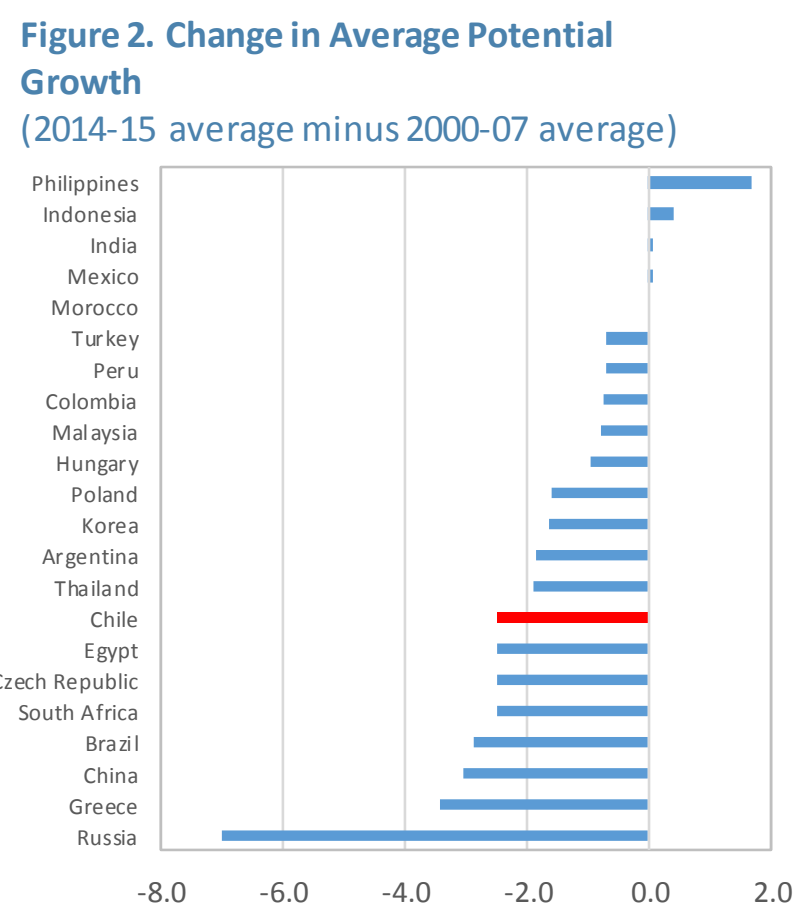
(2015) shows that potential-output growth has slowed down significantly in many advanced and emerging market economies - the slowdown in EMs has been particularly acute in recent years.

The recent decline in potential growth corresponds to an estimated output gap which is only slightly negative at the end of the sample, as shown in Figure 4. There is also considerable uncertainty surrounding this estimate, and our calculations suggest that the 95 percent confidence range is from approximately -2 to +1 percent. $^{14}$

Looking back over history, there is a strong correspondence between the MVF's estimates of the output gap and the unemployment-rate gap, as these processes are related and jointly identified by the filter

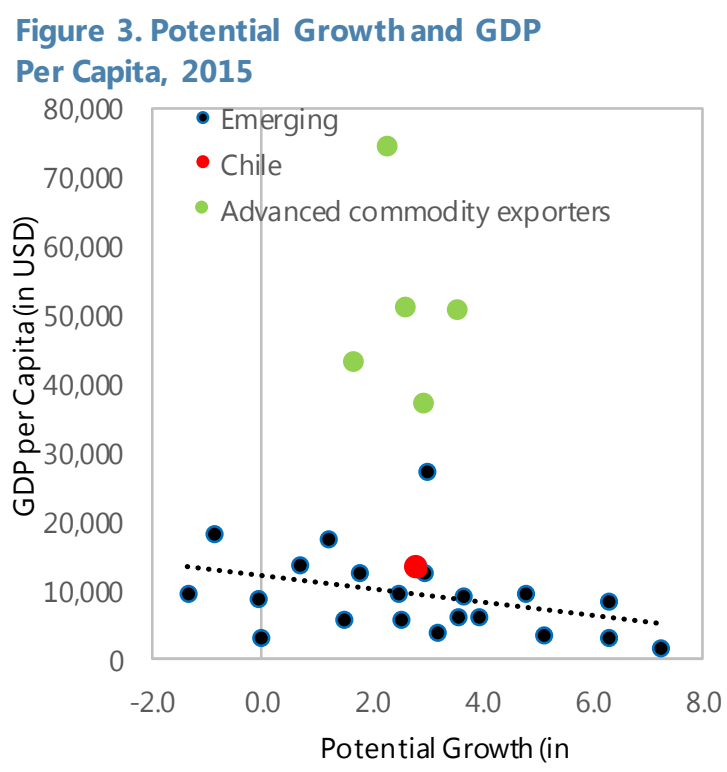
(through estimates of potential output and

\footnotetext{
${ }^{13}$ For Chile, we plot only the non-mining sector potential growth slowdown in the figures.

${ }^{14}$ Confidence bands around point estimates are presented in an appendix (section B).
} 
the NAIRU). There is also a relationship between inflation rates and the output gap, particularly in the lead-up to the global financial crisis, the GFC itself, and the subsequent recovery period. More recently, elevated inflation rates since 2014 have not been associated with a marked positive output gap, as the MVF tends to treat these as arising from inflation shocks, rather than excess demand. ${ }^{15}$ This result coincides with the analysis of Perez Ruiz (2016) which finds an important role for exchange-rate pass-through as opposed to economic slack in determining inflation in Chile, particularly in recent years.

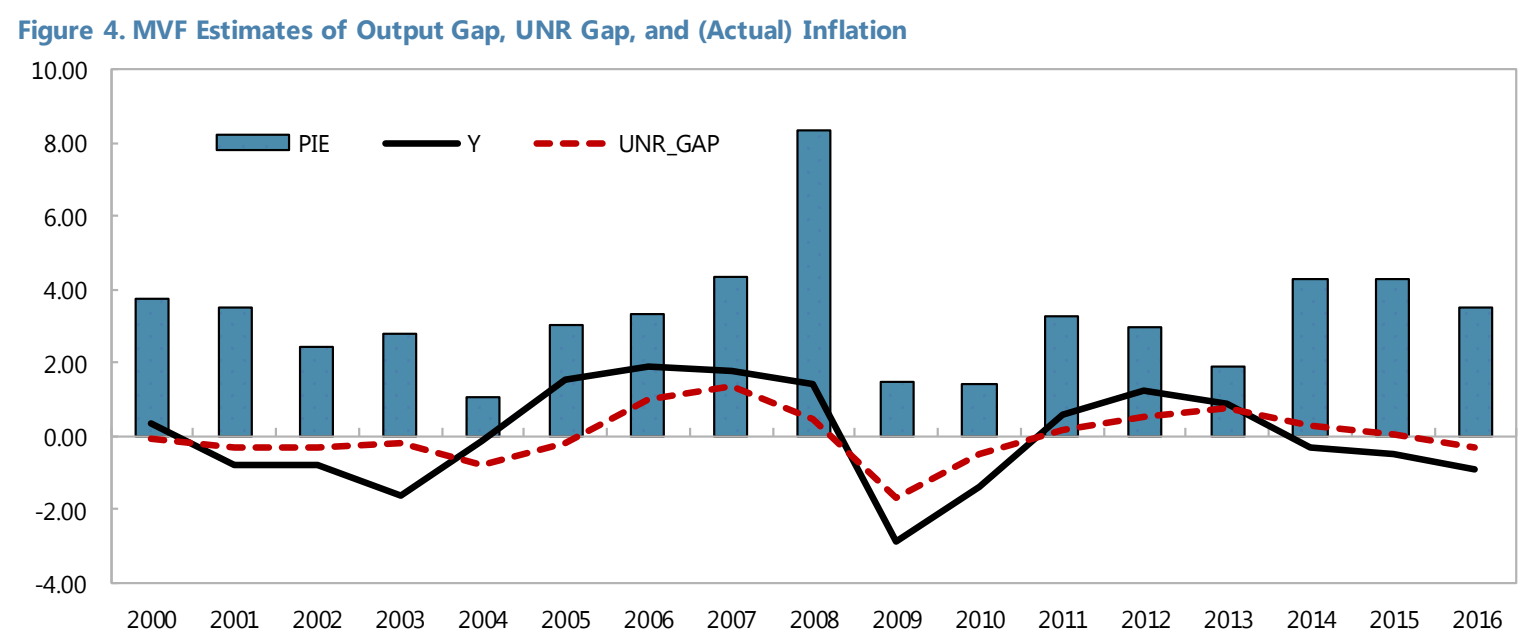

\section{A.2. MVF estimation results: mining sector}

Figure 5 shows the time-series estimates of potential growth for the mining sector. Parameters' estimates are shown in Appendix A, Table A1. Potential growth increased steadily over the course of much of the past decade (albeit, from a negative initial growth rate), reflecting elevated copper prices and (presumably) an expansion of capacity in the mining sector-we will explore the drivers of this increase later in this section when we turn to the production-function accounting exercise.

\footnotetext{
${ }^{15}$ We explore an extension to the baseline MVF, where we add exchange-rate changes to the Phillips curve, in Appendix C.
} 
However, more recently, mining-sector potential growth has slowed, albeit gradually, reflecting a slightly delayed response of production decisions to copper price dynamicsprices peaked in 2011, held relatively steady at elevated levels in 2012-13, and then declined

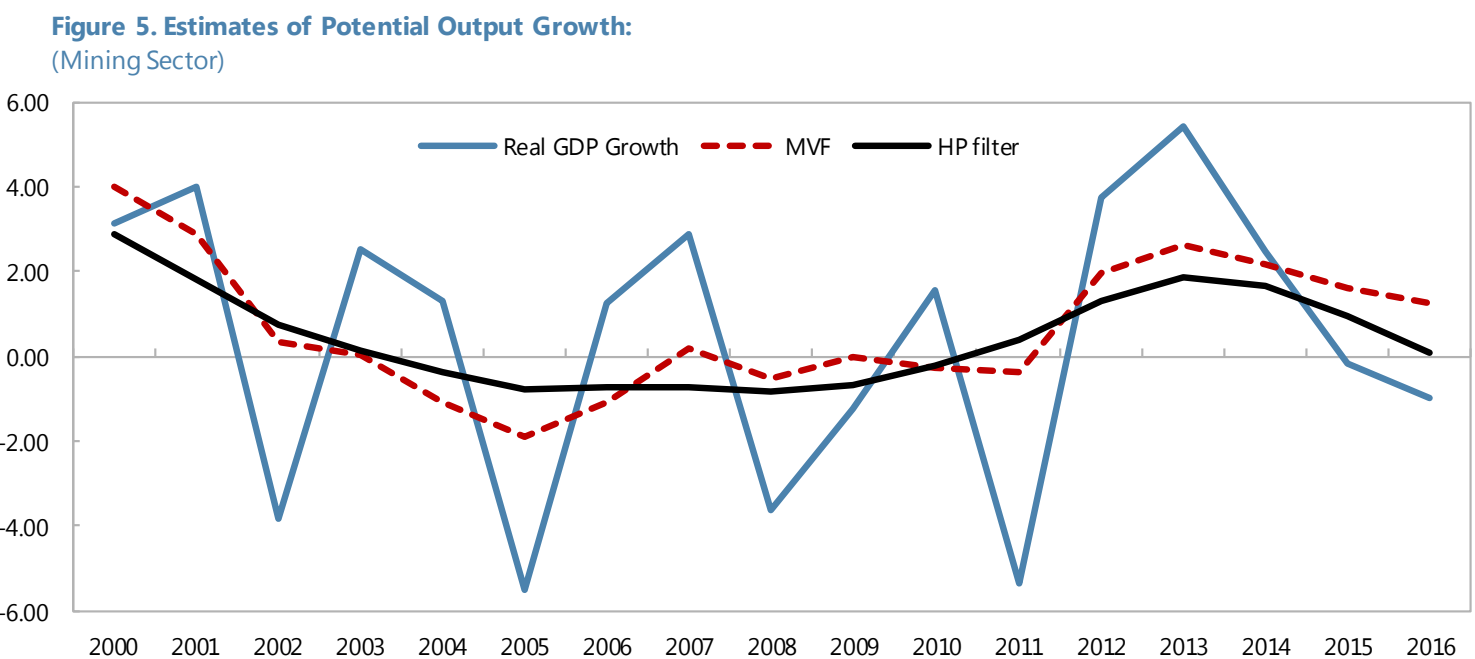

from 2014 onwards. This somewhat sluggish downturn in potential growth is consistent with analysis in IMF (2010), which points out that supply is typically slow to respond to price changes, due to lags in the exploration and capitalinvestment processes.

More broadly, the positive correlation between our estimates of mining-sector potential growth and copper prices is consistent with both Aslam and others (2016) — who find that potential output comoves with the commodity terms of trade - and Harchaoui and Lasserre (2001), who show that investment in Canadian copper mines is a positive function of prices (among other factors).

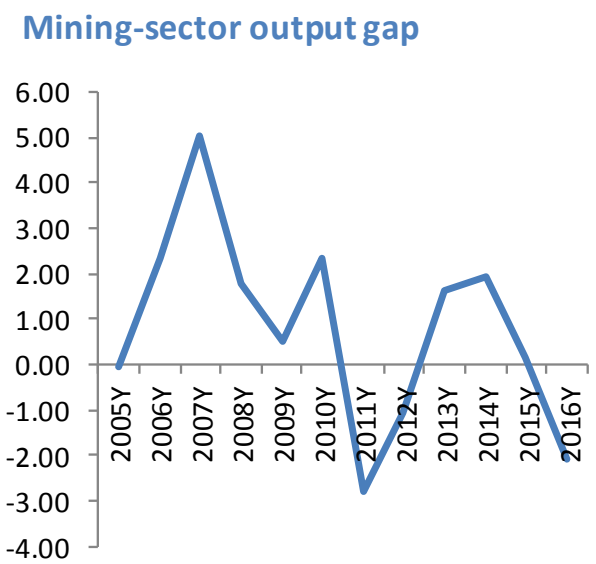

The output gap estimate for the mining sector indicates that excess capacity has emerged in 2015-16, as depicted in the text figure.

\section{B. Decomposition of estimates using a production-function approach}

One drawback of the MVF approach is that it does not offer an interpretation of the drivers of potential growth. In order to delve into this issue, the potential-growth estimates from the MVF are decomposed using a Cobb-Douglas production-function approach (similar to the approach in IMF (2015) and many other studies). This approach allows for an accounting of the drivers of potential growth over history. In addition, it allows us to provide more theoretical 
underpinnings for future course of structural, low-frequency variables and perform analysis of alternative policies scenarios, which would not be possible by simply using the MVF. ${ }^{16}$

Specifically, the production-function approach entails splitting potential output $\left(\bar{Y}_{t}\right)$ into contributions from capital $\left(K_{t}\right)$, potential (human-capital augmented) labor $\left(\bar{H}_{t} \bar{L}_{t}\right)$, and potential total-factor-productivity $\left(\bar{A}_{t}\right.$, which is the Solow residual) using a standard CobbDouglas production-function. ${ }^{17}$ More specifically, the production function used is as follows:

$$
\bar{Y}_{t}=\bar{A}_{t} K_{t}^{\alpha}\left(\bar{H}_{t} \bar{L}_{t}\right)^{(1-\alpha)}
$$

And labor inputs are measured by:

$$
\bar{L}_{t}=N_{t} *\left(1-\bar{U}_{t}\right) * \overline{l f p}_{t} * \text { Hours }
$$

where $\mathrm{N}_{\mathrm{t}}$ is working-age population, $\bar{U}_{t}$ is the non-accelerating inflation rate of unemployment (NAIRU, which is estimated jointly with potential output by the MVF), $\overline{l f p}_{t}$ is the potential labor-force participation rate, and Hours is actual average weekly hours worked. The productivity-augmenting effect of human capital $H$ has been measured in the literature (see Bils and Klenow, 2000) through a relationship between an individual's schooling level and her labor earnings:

$$
H_{t}=\frac{\theta}{1-\mu} s_{t}^{1-\mu}
$$

\footnotetext{
${ }^{16}$ The MVF approach is less well-suited to constructing a forecast, since it does not have any structure regarding the equilibrium processes in the model, and hence its forecasts would simply reflect naïve reversion to the historical mean growth rate (or specified value of $G^{S S}$ over a number of years).

${ }^{17}$ Given actual data on $K_{t}$ and estimates of $\bar{Y}_{t}$ and labor $\left(\bar{H}_{t} \bar{L}_{t}\right), \bar{A}_{t}$ (potential total-factor productivity) is solved for as the residual. Capital stock data for the non-mining sector are purged of housing, in order to be consistent with a notion of the economy's 'productive' capital stock (as in Beffy and others, 2006).
}

(continued...) 
Equation (21) transforms schooling level $s$ into labor-efficiency units for production.

Labor and capital shares differ for the mining and non-mining sectors ( $\alpha=0.56$ for non-mining; $\alpha=0.8$ for mining). ${ }^{18}$ The parameters $\theta$ and $\mu$ together capture the curvature and the mean returns to education. In particular, $\mu>0$ indicates decreasing returns to education as in Bils and Klenow (2000).

\begin{tabular}{lr}
\multicolumn{2}{l}{ Parameters in the production function } \\
\hline parameter & value \\
\hline Capital share $(\alpha)$ & 0.8 \\
mining sector & 0.56 \\
non-mining sectors & \\
Human capital & 0.32 \\
$\quad$ mean return $(\theta)$ & 0.58 \\
curvature $(\mu)$ & \\
\hline
\end{tabular}

Potential output growth in the mining sector has been dominated by two opposing forcesstrong investment and capital stock growth rates to maintain production levels in the presence of rapidly declining total-factor productivity (Figure 6). The need for such strong investment growth can be thought of in the context of steadily deteriorating ore grades at Chilean copper mines. As discussed in Aguirregabiria and Luengo (2015) the ore grade at a copper mine deteriorates gradually over time, as more profitable (resource-rich) deposits are mined first. They find that cost of extraction has been increasing during the 2000s, signaling a deterioration of the quality of the ore. In order to maintain production, investment is needed constantly, both in the form of exploration, and infrastructure to extract copper from new ore deposits.

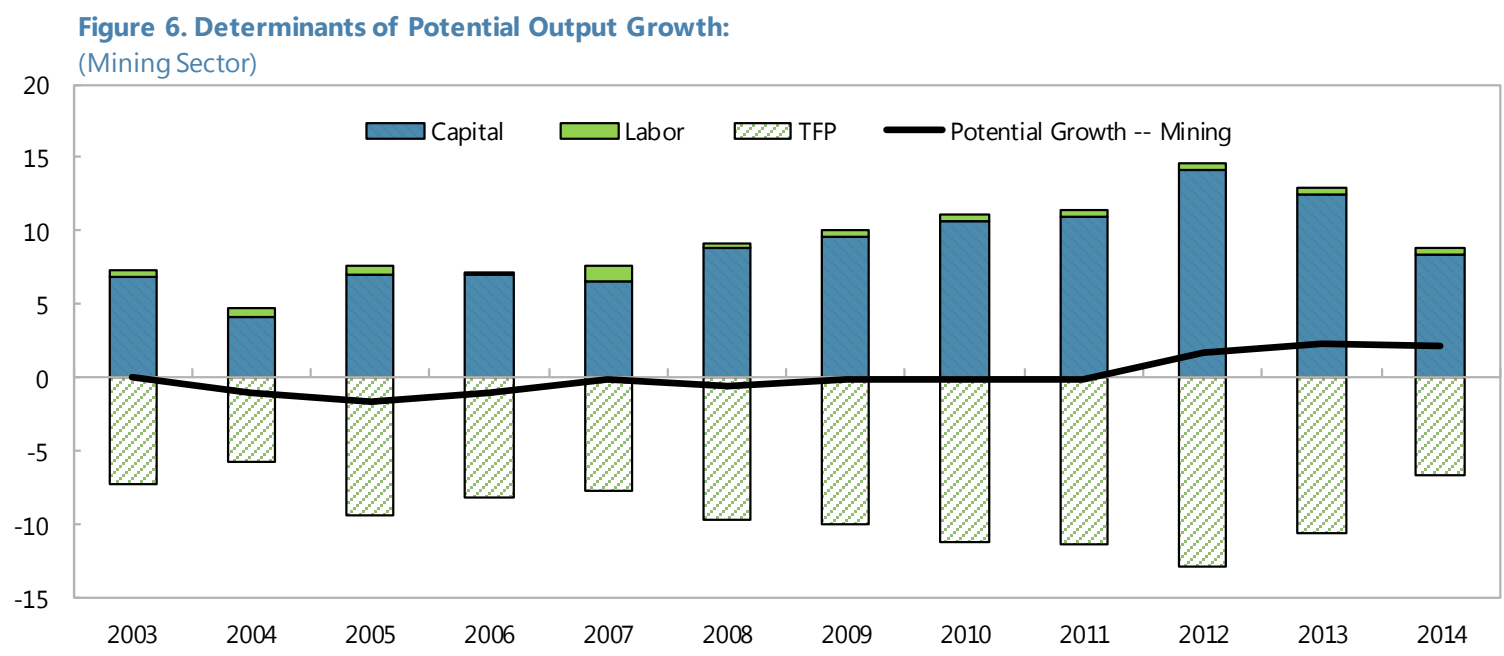

As for the decomposition of potential growth for the non-mining sectors, Figure 7 shows that the recent decline in potential growth has been driven to an important degree by slower

\footnotetext{
${ }^{18}$ These estimates are based on Banco Central de Chile Fall 2014 monetary policy report, where a labor share of 0.52 is assumed for the entire economy. A labor share of 0.2 is assumed for mining (based on estimates from other work), which leaves a residual of 0.56 for the non-mining sector.
} 
capital stock accumulation. ${ }^{19}$ Indeed, relative to 2011, slower capital accumulation explains about one half of the slowdown, whereas slower TFP and labor-input growth account for about 30 and 20 percent of the slowdown, respectively.

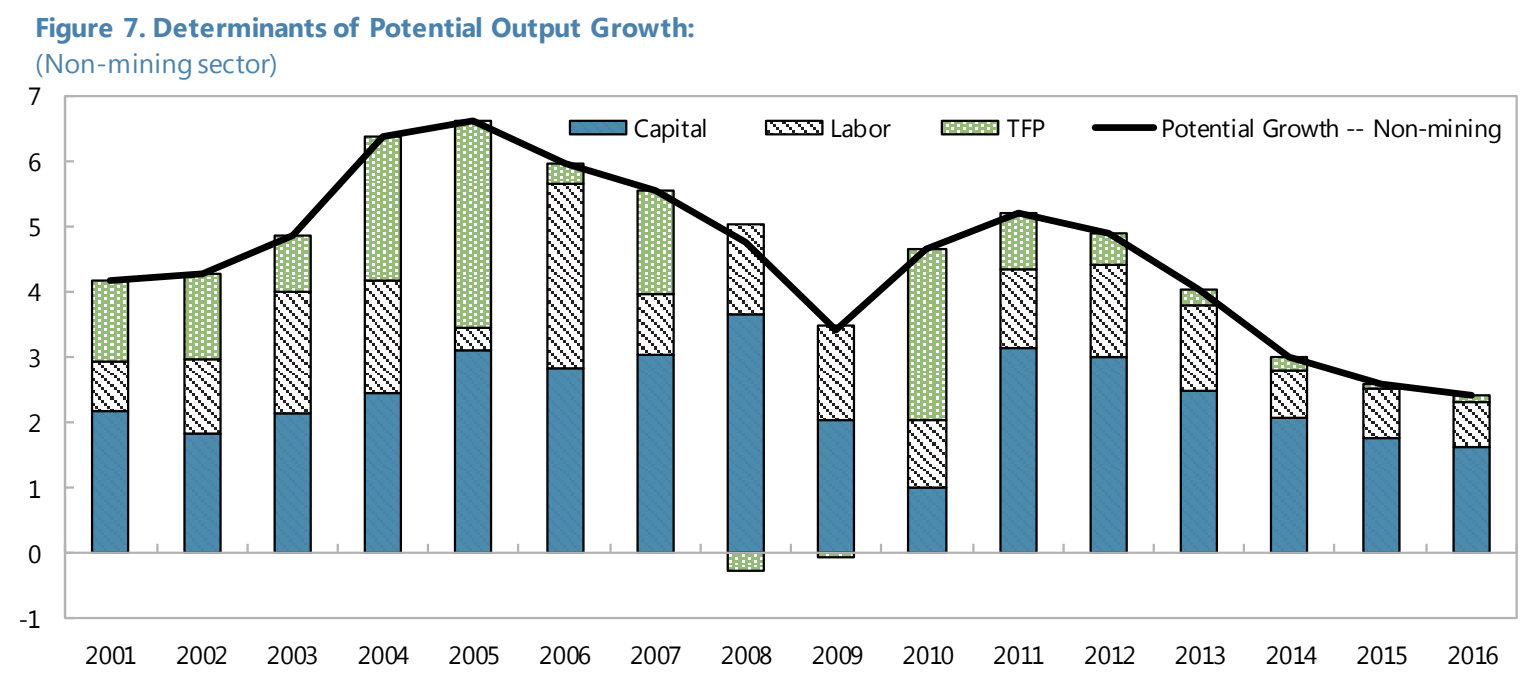

\section{B. What are the factors behind weaker growth in capital accumulation?}

Capital accumulation in Chile has proceeded slowly since 2011 as private investment growth has been lackluster. A previous study showed a pervasive investment slowdown across many emerging markets, especially those in Latin America, in most cases due to adverse external conditions (IMF WHD Regional Economic Outlook, April 2015).

In the case of Chile, the study found that adverse external conditions, namely commodity export prices $(P X)$, global demand $(W G D P)$ and real effective exchange rate $(R E E R)$ dynamics, were important, but that these accounted for just above one-third of the (cumulative) slowdown from 2011 to mid-2014 (see Figure 8). Domestic factors such as low expected profitability (measured by the Tobin's $Q$ ) and tight monetary conditions (mirrored by the lending rate $R$ ) explained the vast majority of the investment growth slowdown. ${ }^{20}$ Partly offsetting these sources of weakness were other domestic factors, such as the volume

\footnotetext{
${ }^{19}$ For capital stock, we use actual data from the Banco Central de Chile until 2014 (net capital stock for nonmining sectors, minus dwellings, at current prices). For 2015 and 2016, we extend estimates of the capital stock holding the depreciation rate from 2014 constant, and taking actual and (WEO) projected investment rates as given.

${ }^{20}$ In the Tobin's theory of investment, (expected) profitability is represented by the shadow marginal value of investment (the Tobin's Q) (see Gilchrist and Himmelberg, 1995). Marginal Q is unobservable and can be proxied by average Q (see Hayashi, 1982). We measure average Q as the ratio between the stock market value and the investment deflator.
} 
of economic activity (proxied by GDP growth) in previous quarters (following theories of the accelerator).

The specification used in the study performs particularly well in some periods but has relatively large unexplained shares of the investment changes in others. For instance, the period 2013Q3 to 2014Q4 present relatively large unexplained components of investment slowdown, which can be attributed to large shocks not captured by the variables in the model specification (see also IMF Staff Report 2015).

This finding is corroborated by Albagli and Luttini (2015), who report that domestic factors played a major role in depressing investment in Chile in the period 2011-14, in some specifications explaining about 80 percent of investment slowdown, while external factors were still important but accounted only for about 20 percent.

To consider the more recent period of weak investment, we extend the model used in IMF (2015) to analyze the determinants of investment growth from late 2014 until 2016. ${ }^{21}$ In contrast to the previous results, we find that more recently the major headwinds to investment growth have been coming from external conditions, such as lower commodityexport prices, higher global uncertainty (VIX, mirroring financial uncertainty) and in particular a depreciated exchange rate, which harms investment since most of Chile's capital goods are imported. Those factors explain close to the two-thirds of the investment dynamics since late 2014. Domestically, favorable monetary conditions and an improvement in expected profitability relative to previous years have sparked a positive incentive to invest, and provided some partial offset to the weakness from external conditions.

\footnotetext{
${ }^{21}$ The vector autoregression (VAR) estimated is the following: $Y_{t}=A Y_{t-p}+\varepsilon_{t}$ Where the vector $Y$ comprises: (log difference) INV, WGDP, REER, PX, VIX, Q, GDP, R and p=2.
} 
Figure 8: Decomposition of investment growth

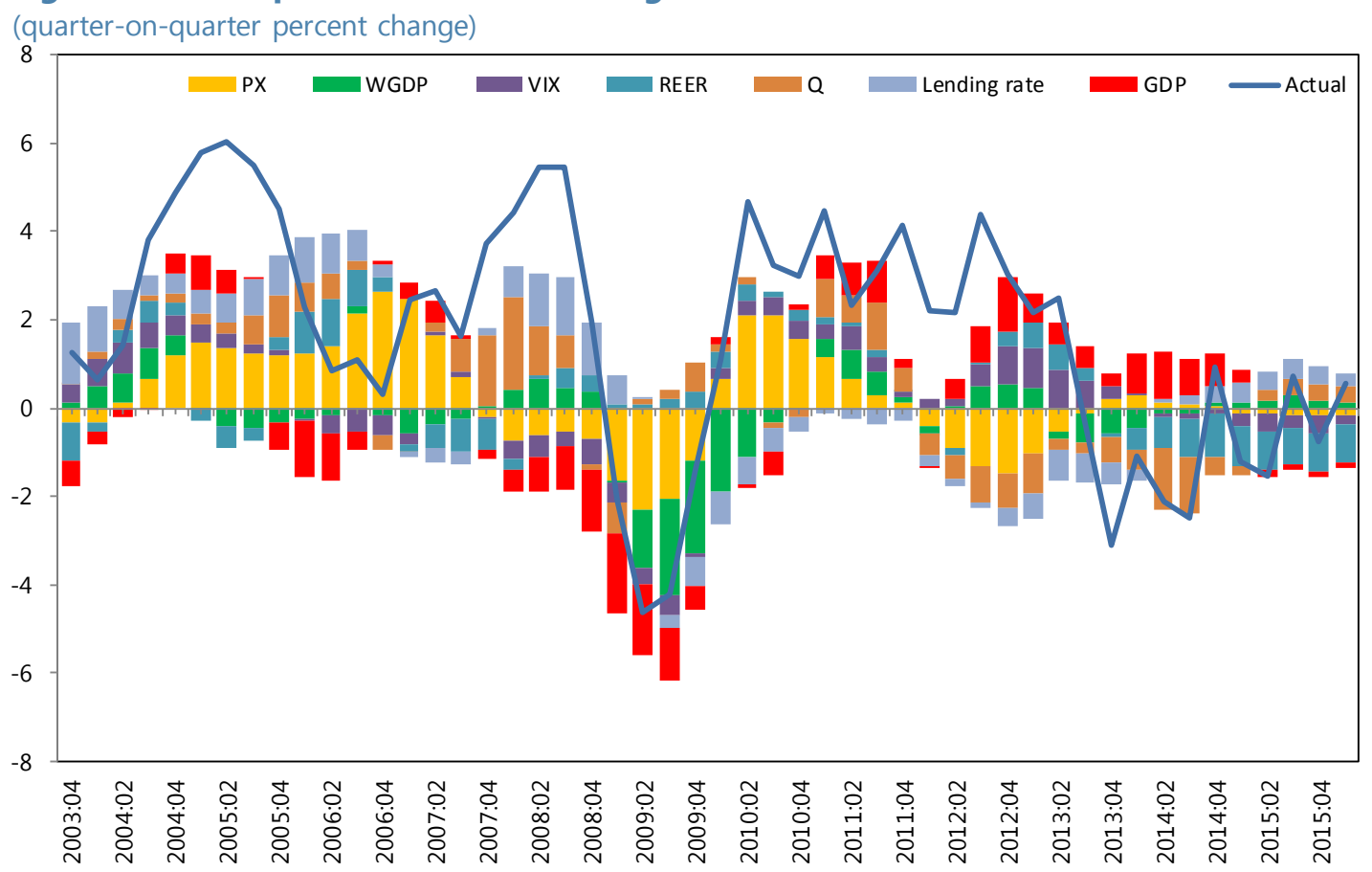

Source: Haver analytics, INS and IMF staff calculations

\section{What explains the deceleration in TFP growth?}

The slowdown in TFP is likely related to capacity bottlenecks in several key sectors, besides mining. Corbo (2014) presents an in-depth analysis of the particular sectors contributing to weak productivity growth and finds that inefficiencies in crucial industries, such as manufacturing, transportation and utilities are among the largest contributors to the TFP growth : the 1990 s versus the 2000 s aggregate slowdown in TFP. Since the beginning of the 2000s, TFP growth declined by $0.8,3.0$ and $2.3 \mathrm{ppt}$ in manufacturing, transportation and utilities sectors, respectively. This has implied a stark change in productivity at the aggregate level between the 1990 s and the 2000 s.

The rapid growth of productivity during the early 1990s is mostly related to reallocation of factors towards high-performance sectors, specifications

\begin{tabular}{lrrrr} 
period & \multicolumn{1}{l}{ a } & \multicolumn{1}{l}{ b } & \multicolumn{1}{l}{ c } \\
\hline $1987-1991$ & 2.0 & 2.0 & 2.0 & 2.4 \\
$1992-1997$ & 2.5 & 2.9 & 2.4 & 0.4 \\
$1998-2003$ & -0.7 & -1.0 & -0.3 & -1.4 \\
$2004-2008$ & 0.5 & 0.0 & 1 & -0.4 \\
$2009-2012$ & -0.7 & -4.0 & -1.2 & 0.0
\end{tabular}

Source: Corbo (2014)

Note: specifications: a) without accounting differently for ICT capital; b) treating differently ICT capital; c) adjusting for energy-cost induced utilization of capital; d) aggregating five main sectors (manufacturing, construction, commerce transportation and financial services including ICT, fostered also by large privatizations. The subsequent decline in aggregate TFP growth starting in 1998 is likely related to a slower reallocation of factors, especially labor, to high-performance sectors, owing to the scarcity of skilled workers and declining 
productivity in key sectors, such as transportation and utilities, partly linked to high levels of electricity prices and large infrastructure gaps in transportation (Santoro, 2015). ${ }^{22}$ Corbo (2014) surveys several approaches for estimating TFP growth at the aggregate level, including by previous literature. Independent of the specification or data used, he shows that TFP growth could be up to $2 \mathrm{ppt}$ lower starting in the 2000s (see table). Structural weaknesses in human capital and bottlenecks in infrastructure are likely to continue holding back potential growth in the next few years.

\section{What is behind low labor-input growth?}

The production-function accounting of potential growth shows that declining labor inputs have played a non-trivial role in the recent slowdown of potential growth. Figure 9 breaks the evolution of the labor input into its components (from equation 20) and shows an important role for declines in average hours worked in depressing labor-input growth rates. However, on aggregate, the trend towards shorter work weeks is being offset by steady increases in human capital. Estimates of the NAIRU have been quite steady over the sample period and contribute relatively little to the decline. Finally, population growth rates are slowing, implying a very gradual decline in labor-force growth. At the same time, growth in participation rates have fallen substantially in recent years, providing less support than they did for much of the previous decade. This trend warrants closer inspection as it reverses an until recently positive and growing contribution to potential growth. A discussion of the drivers of participation rates, and the implications of demographic factors for the evolution of labor inputs, and medium-term potential growth, is presented in a companion paper (Blagrave and Santoro, 2016).

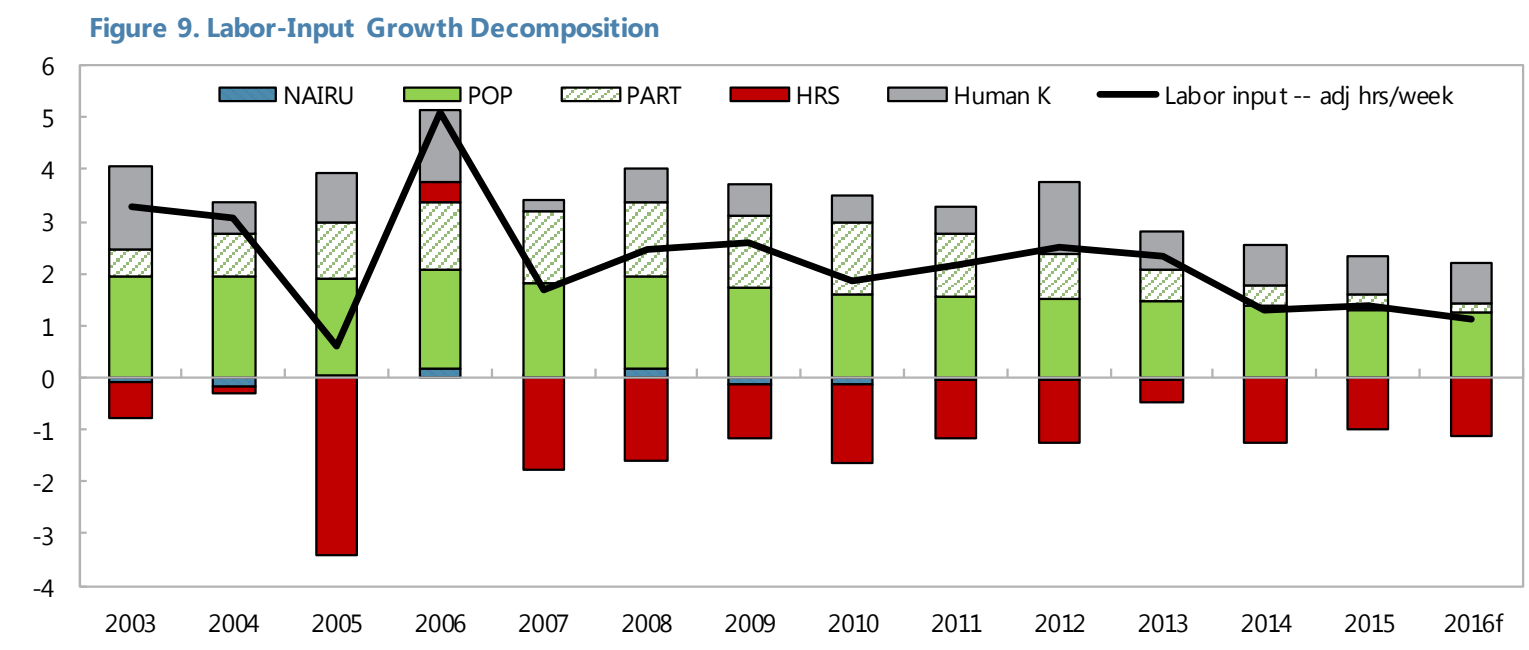

\footnotetext{
${ }^{22}$ Since the end of the 1990s, Chile has suffered a series of negative shocks that have increased the cost of electricity generation. Several droughts affected the electricity generation in the hydro segment, starting in 1998-1999. In addition, in 2004 Argentina sudden stopped exports of natural gas to Chile increasing the dependency of energy on oil, whose prices continued to increase during the 2000s.
} 


\section{CONCLUSION}

In this paper, we estimate the structural components of the recent slowdown in economic growth in Chile by using a MVF approach, following previous work by Blagrave and others (2015), IMF (2015), and Benes and others (2010). We extend the approach in the previous literature by studying mining and non-mining sectors separately. We also use a productionfunction approach to study whether the drivers of potential growth are different in the two types of sectors.

Our estimates of potential output in Chile suggest that an important part of the recent growth slowdown has been structural, with potential-output growth slowing to $2 \frac{1}{2}$ percent in recent years in the non-mining sectors. Different from previous literature on EMs, we find that slower potential growth has been driven primarily by weaker capital accumulation in recent years, as investment has slowed considerably. In addition, labor-input growth has also played an important role in accounting for the deceleration, as previous gains from accelerating participation rates have stalled, and working-age population growth rates have trended lower. In the mining sector, we find that a long-standing issue of low productivity growth is behind low estimates of potential output - this can be attributed to gradually declining ore grades as more profitable deposits are extracted first.

Headwinds in the form of lower copper prices, weak external demand, and infrastructure bottlenecks pose challenges for medium-term growth. Plausibly, the potential growth rate can increase over the medium-term as investment and productivity growth rates are substantially below levels consistent with Chile's recent path and fundamentals. We explore this and other issues in a companion paper (Blagrave and Santoro, 2016). 


\section{REFERENCES}

Aguiar, M., and G. Gopinath, 2007, "Emerging Market Business Cycles: The Cycle Is the Trend”, Journal of Political Economy, University of Chicago Press, vol. 115, pp. 69102

Aguirregabiria, V., and A. Luengo, 2015, “A Microeconometric Dynamic Structural Model of Copper Mining Decisions," http://isites.harvard.edu/fs/docs/icb.topic1465230.files/copper_mining_victor_271120 14.pdf

Albagli E and E. Luttini, 2015, Expectativas, Incertidumbre, e Inversión en Chile: Evidencia Macro y Micro de la Encuesta IMCE, Mimeo Central Bank of Chile, June 2015.

Albagli, E, and A. Naudon, 2015, “¿De qué hablamos cuando hablamos de producto potencial?"

Alberoa, E., A. Estrada, and D. Santabarbara, 2013, "Growth Beyond Imbalances. Sustainable Growth Rates and Output Gap Reassessment," Banco de Espana Documentos de Trabajo no. 1313

Aslam, A., S. Beidas-Strom, R. Bems, O. Celasun, S. Kilic Celik, and Z. Koczan, 2016, "Trading on Their Terms? Commodity Exporters in the Aftermath of the Commodity Boom," IMF Working Paper WP/16/27

Australian Council of Trade Unions, 2013, “A Shrinking Slide of the Pie," Working Australia Papers, no. 1 of 2013.

Barnett, R., S. Kozicki, and C. Petrinec, 2009, "Parsing Shocks: Real-Time Revisions to Gap and Growth Projections for Canada," Federal Reserve Bank of St. Louis Review, pp. 247-265.

Beffy, P-O, P. Ollivaud, P. Richarson, and F. Sedillot, 2006, "New OECD Methods for Supply-Side and Medium-Term Assessments: A Capitol Services Approach," OECD Working Paper 482, Paris.

Benes, J., K. Clinton, R. Garcia-Saltos, M. Johnson, D. Laxton, P. Manchev, and T. Matheson, 2010, "Estimating Potential Output with a Multivariate Filter," IMF Working Paper WP/10/285.

Benes, J., and P. N'Diaye, 2004, “A Multivariate Filter for Measuring Potential Output and the NAIRU: Application to The Czech Republic," IMF Working Paper WP/04/45.

Blagrave, P., R. Garcia-Saltos, D. Laxton, and F. Zhang, 2015, “A Simple Multivariate Filter for Estimating Potential Output,” IMF Working Paper WP/15/79. 
Blagrave, P. and M. Santoro, 2016, “A Cohort Model for Estimating Trend Participation Rates in Chile," IMF Working Paper, forthcoming.

Borio, C., P. Disyatat, and M. Juselius, 2013, "Rethinking Potential Output: Embedding Information about the Financial Cycle,” BIS Working paper no. 404.

Congressional Budget Office (CBO), 2001, “CBO's Method for Estimating Potential Output: an Update," CBO Paper, August 2001.

Cotis, JP, J. Elmeskov, and A. Mourougane, 2004, "Estimates of Potential Output: Benefits and Pitfalls from a Policy Perspective." Published in Euro Area Business Cycle: Stylized Facts and Measurement Issues, pp. 35-60.

D’Auria, F, C. Denis, K. Havik, K. McMorrow, C. Planas, R. Raciborski, W. Roger, A. Rossi, 2010, "The production function methodology for calculating potential growth rates and output gaps" European Commission Economic Papers No 420, July 2010.

De Gregorio, Jose, 2015, "From Rapid Recovery to Slowdown: Why Recent Economic Growth in Latin America has been slow" Peterson Institute for International Economics PB15-6.

De Masi, P. R., 1997, “IMF Estimates of Potential Output: Theory and Practice,” IMF Working Paper WP/97/177.

Eyraud, L., 2015, "End of the Supercycle and Growth of Commodity Producers: The Case of Chile," IMF Working Paper WP/15/242.

Giorno, C, P. Richardson, D. Roseveare, and P. van den Noord, 1995, "Estimating Potential Output, Output Gaps and Structural Budget Balances,” OECD Working Paper no. 152

Hamilton, J, 1994. Time Series Analysis, Princeton University Press, New Jersey.

Hodrick, R.J., and E.C. Prescott, 1997, "Post-War U.S. Business Cycles: An Empirical Investigation," Journal of Money, Credit and Banking, Vol. 29(1), pp. 1-16.

Hotelling, H, 1931, “The Economics of Exhaustible Resources”, Journal of Political Economy 39 (2), pp 137-175.

International Monetary Fund (IMF), 2010, "Recovery, Risk, and Rebalancing” World Economic Outlook, Chapter 1, October, Washington. 
(IMF), 2013, “The Dog That Didn't Bark: Has Inflation Been Muzzled or Was It Just Sleeping?” World Economic Outlook, April, Washington. (IMF), 2015, "Where are we Headed? Perspectives on Potential Output" World Economic Outlook, April, Washington. (IMF), 2015, "Recent Investment Weakness in Latin America: Is There a Puzzle?" WHD Regional Economic Outlook, Chapter 4, April, Washington.

Kuttner, K. N., 1994, "Estimating Potential Output as a Latent Variable" Journal of Business and Economic Statistics, Vol. 12, pp. 361-68.

Laxton, D., and R. Tetlow, 1992, “A Simple Multivariate Filter for the Measurement of Potential Output,” Technical Report no. 59 (Ottawa: Bank of Canada).

Ljung, L., 1999, “System Identification: Theory for the User,” Prentice-Hall: New Jersey.

Mishkin, F.S., 2007, “Inflation Dynamics,” Annual Macro Conference, Federal Reserve Bank of San Francisco, March. http://www.federalreserve.gov/newsevents/speech/Mishkin20070323a.htm

Okun, A.M., 1962, "Potential GNP: Its Measurement and Significance," in Proceedings of the Business and Economic Statistics Section, pp. 98-104 (Washington: American Statistical Association).

Perez Ruiz, 2016, "Outside the Band: Depreciation and Inflation Dynamics in Chile" IMF Working Paper WP/16/129

Prachowny, M., 1993, "Okun's Law: Theoretical Foundations and Revised Estimates," The Review of Economics and Statistics, Vol. 75, No. 2, pp. 331-336.

Ravn, M. O., and Harald Uhlig, 2002, "Notes on Adjusting the Hodrik-Prescott Filter for the Frequency of Observations," The Review of Economics and Statistics, Vol. 82, No. 2, pp. 371-380.

Vergara, Rodrigo, "Chile's growth opportunities and challenges to development," Keynote speech given at the Latin American Cities Conference, April 28, 2016

Vetlov, I., T. Hledik, M. Jonsson, H. Kucsera, and M. Pisani, 2011. "Potential Output in DSGE Models," ECB Working Paper Series No. 1351. 
Wets, Roger J-B, and I. Rios, 2015, "Modeling and Estimating Commodity Prices: Copper Prices," Mathematics and Financial Economics, October, Volume 9, Issue 4, pp 247 270. 


\section{APPENDIX}

\section{A. Estimation priors, posteriors, and data sources}

Priors on the parameters in both the mining and non-mining sector MVFs are taken from previous work on estimating potential output for a wide range of countries (Blagrave and others, 2015). Although estimates of potential output and the output gap are robust to the selection of different prior values for many of these parameters and shock-term standard errors, results are somewhat sensitive to the selection of values for RES_Y,

RES_LGDP_BAR, and RES_G. For the variances of these shock terms, our prior is that there is a more important role for shocks to potential output in explaining the business cycle, as suggested in the literature (Aguiar and Gopinath, 2007) — this motivates a slightly higher emphasis on shocks to the level and growth rate of potential output in Chile, relative to what would come from an HP filtration of the data using a 'standard' smoothing parameter (lambda=6.25 for annual data, Ravn and Uhlig, 2002). Our selection of priors for these variables is consistent with previous work on estimating potential output in emerging market economies, and ultimately we allow for some variation in the estimation of these parameters' standard error terms, as shown in Table A1.

Table A1. Priors and Parameter Estimates

\begin{tabular}{|c|c|c|c|}
\hline \multicolumn{4}{|c|}{ Priors and Posterior Estimates, Non-Mining Sector } \\
\hline Prior & Prior Standard Deviation & Posterior Estimate \\
\hline lambda & 0.25 & 0.1 & 0.16 \\
phi & 0.25 & 0.10 & 0.26 \\
theta & 0.60 & 0.10 & 0.61 \\
growth_SS & 0.10 & 0.10 & 0.10 \\
tau1 & 0.30 & N/A & 4.00 \\
tau2 & 0.30 & 0.10 & 0.33 \\
tau3 & 0.10 & 0.10 & 0.30 \\
tau4 & 0.10 & 0.01 & 0.10 \\
unr_SS & N/A & 0.01 & 0.10 \\
RES_LGDP_BAR & 0.50 & N/A & 7.06 \\
RES_G & 0.50 & 0.01 & 0.33 \\
RES_Y & 1.00 & 0.01 & 0.51 \\
RES_UNR_GAP & 0.50 & 0.01 & 1.27 \\
RES_UNR_BAR & 0.10 & 0.01 & 0.40 \\
RES_G_UNR_BAR & 0.10 & 0.01 & 0.01 \\
& & 0.01 & 0.03 \\
\hline
\end{tabular}




\begin{tabular}{|c|c|c|c|}
\hline \multicolumn{4}{|c|}{ Priors and Posterior Estimates, Mining Sector } \\
\hline \multicolumn{1}{|c|}{ Prior } & Prior Standard Deviation & Posterior Estimate \\
\hline lambda & 0.25 & 0.10 & 0.50 \\
phi1 & 0.60 & 0.10 & 0.52 \\
theta & 0.10 & 0.10 & 0.06 \\
growth_SS & N/A & & 1.00 \\
rho1 & 0.10 & 0.05 & 0.07 \\
phi2 & 0.10 & 0.01 & 0.09 \\
mu & 0.05 & 0.01 & 0.05 \\
Icopper_bar_SS & N/A & & 550.00 \\
RES_LGDP_BAR & 0.50 & 0.01 & 0.42 \\
RES_G & 0.50 & 0.01 & 0.63 \\
RES_Y & 1.00 & 0.01 & 1.80 \\
RES_LPCOPPER_GAP & 10.00 & 0.40 & 16.89 \\
RES_LPCOPPER_BAR & 5.00 & 0.40 & 8.09 \\
\hline
\end{tabular}

Table A2. Data Sources

\begin{tabular}{|ll|}
\hline \multicolumn{1}{|c|}{ Indicator } & \multicolumn{1}{c|}{ Source } \\
\hline Inflation expectations & Consensus Economics \\
$\begin{array}{l}\text { Gross Domestic Product growth expectations } \\
\text { (constant prices) }\end{array}$ & Consensus Economics \\
Gross Domestic Product (constant prices) & IMF, World Economic Outlook Database \\
CPI Inflation & IMF, World Economic Outlook Database \\
$\begin{array}{l}\text { Unemployment Rate } \\
\text { Copper Price (USD/Ib) }\end{array}$ & IMF, World Economic Outlook Database \\
Net capital stock (constant prices), mining and & IMF, World Economic Outlook Database \\
non-mining sectors & \\
Working age population & \\
& United Nations World Population Prospects \\
Participation rate; average weekly hours worked & International Labor Organization \\
\hline
\end{tabular}




\section{B. Uncertainty Inherent in Potential Output and Output Gap Estimates}

As indicated in the main text, estimating unobservable variables is a difficult task, and brings with it considerable uncertainty. In order to give a rough impression of one type of uncertainty inherent in these estimates, we take (1000) draws of the latent variables in our model, taking as given the estimated parameterization and structure of this model. Below, we plot our point estimates of potential growth and the output gap, as well as 95 percent confidence bands around these estimates, obtained from the aforementioned draws of the latent variables.

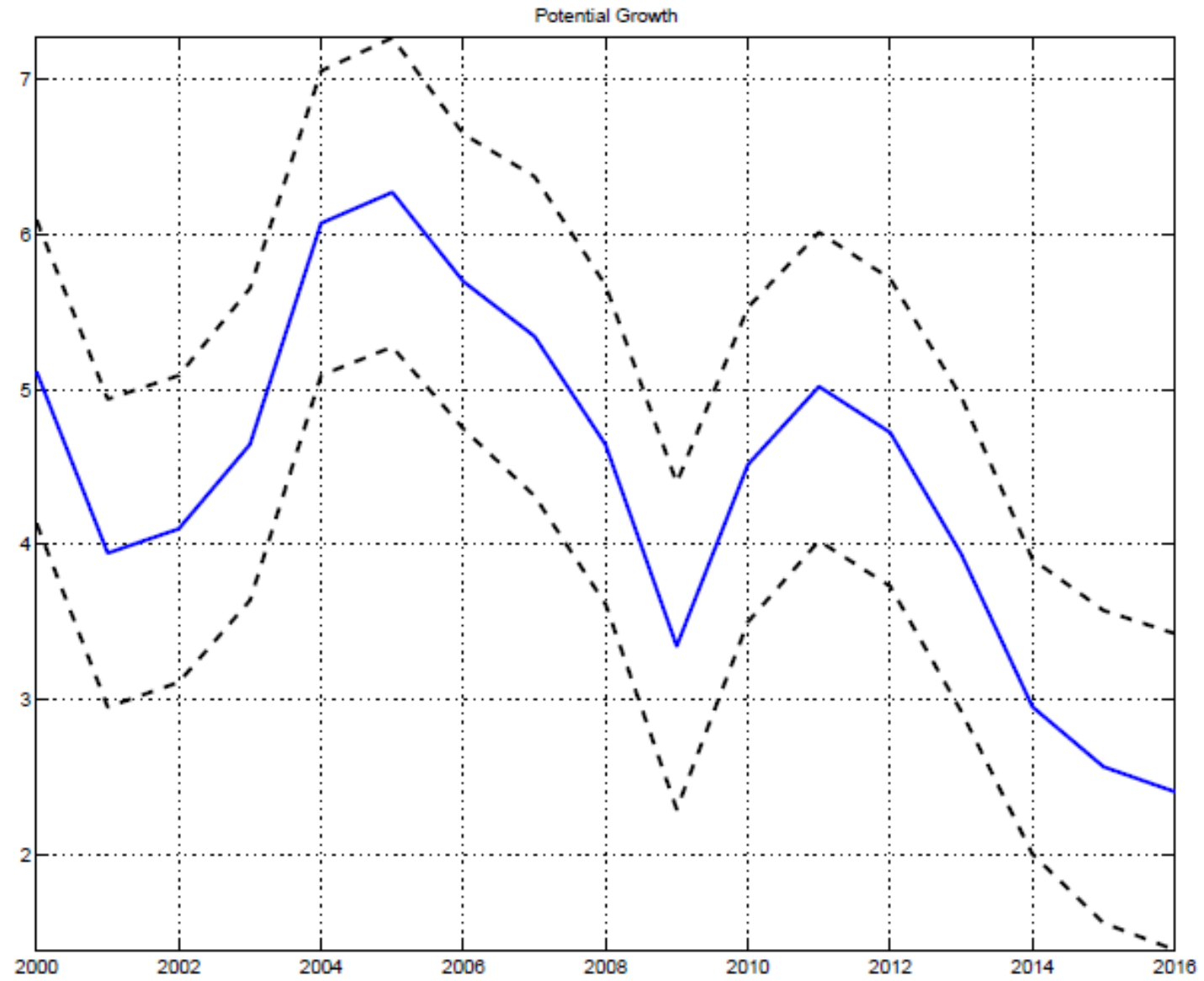




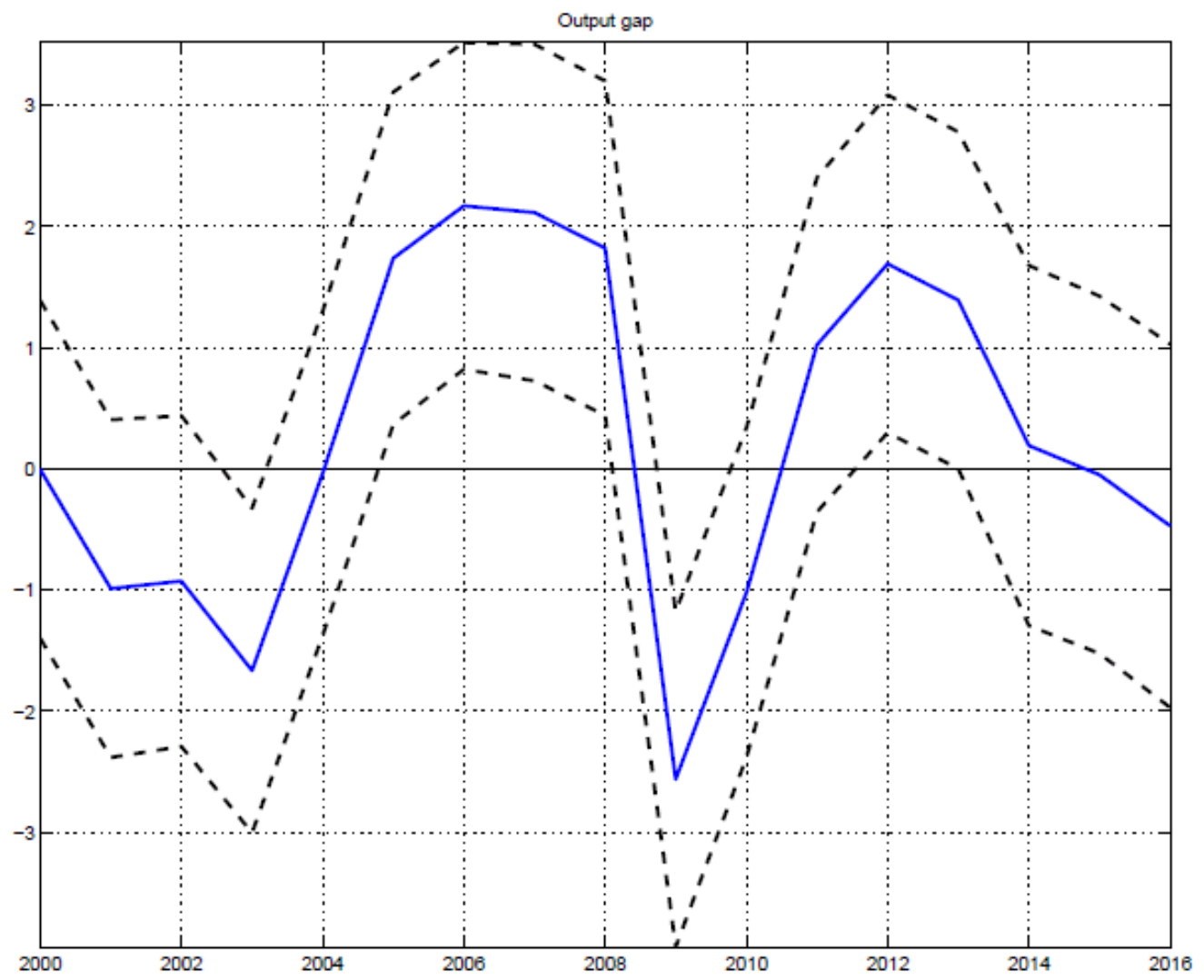

\section{Robustness Testing and Alternate Specifications}

In this section, we illustrate the sensitivity of our estimates to several alternative parameterizations and specifications. Estimates are shown to be relatively invariant to small changes to model structure, and plausible changes to selected parameters.

\section{Adding exchange rates to the Phillips Curve}

To more firmly establish our point from footnote 6 in the main text, we investigate the impact on estimates of potential output and the output gap of adding a term for changes in the exchange rate to the Phillips curve (non-mining sector specification). In particular, we estimate a version of the MVF which preserves equations 1-11 as they are in the main text, with the exception of the following change to the Phillips curve:

$$
\pi_{t}=\lambda \pi_{t+1}+(1-\lambda) \pi_{t-1}+\beta y_{t}+\rho D R X_{t}+\varepsilon_{t}^{\pi},
$$

where $D R X_{t}$ is the change in the exchange rate in period $\mathrm{t}$, and $\rho$ is a parameter dictating the degree of pass-through associated with this change. Experimenting with a range of values for $\rho$ suggests that the estimates of both potential output and the output gap are invariant to the inclusion of exchange rates - however, as expected, the addition of the exchange rate (and a large value of $\rho=0.2$ ) does reduce the size of inflation shocks in the MVF (equivalently, this allows for a better prediction of inflation by the MVF). 

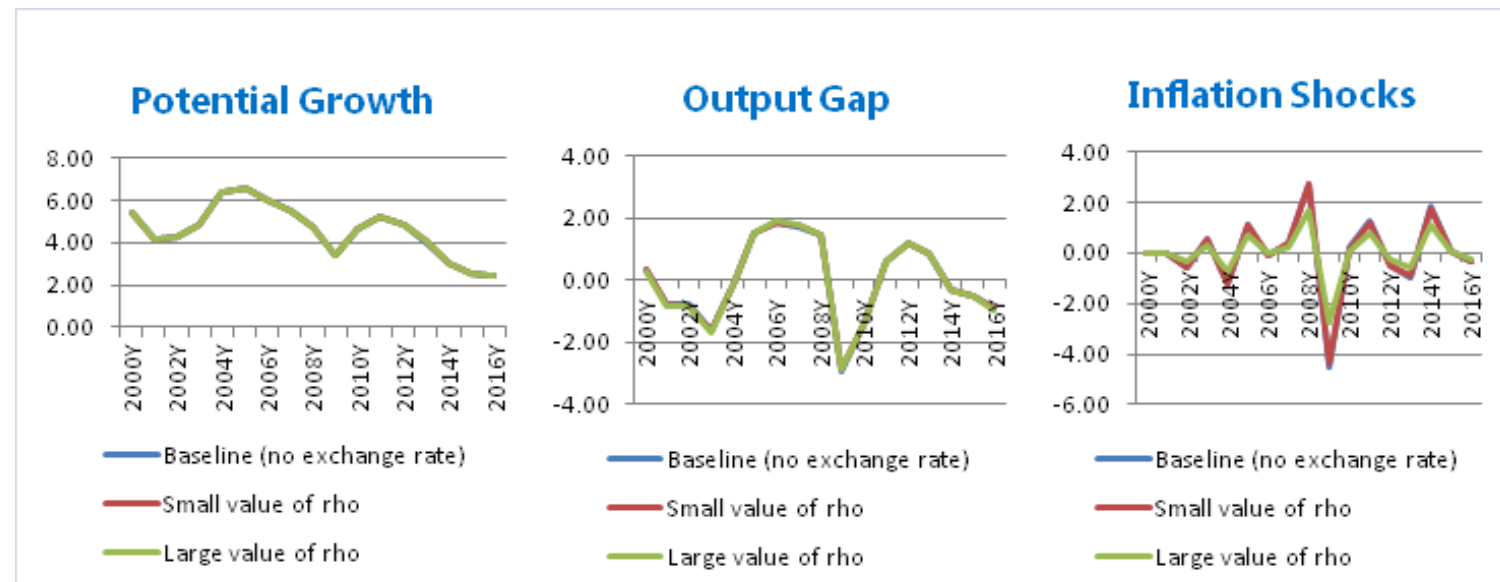

\section{Alternate values of steady-state growth}

As noted in the main text, footnote 5, the term $G^{S S}$ used in the MVF is not derived from theory. To illustrate the sensitivity of MVF estimates of potential output and the output gap to different values of this term, we present results below for three specifications, where $G^{S S}$ takes on the values of 4, 5, and 6. In all cases, the structure of the MVF (non-mining sector) is identical to what was presented in the main text, equations 1-11.
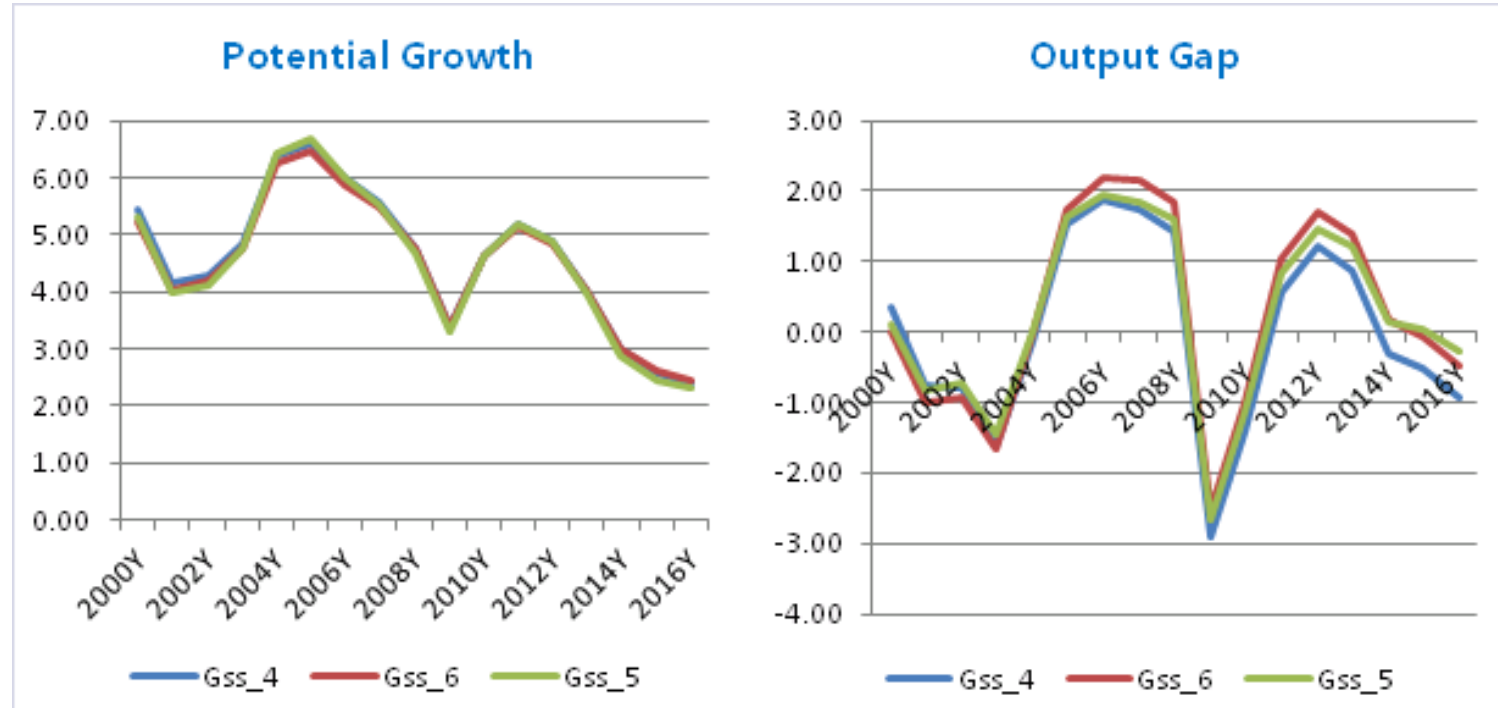

As shown, estimates of potential growth are very robust to different values of $G^{S S}$, whereas estimates of the output gap are moderately robust - for example, the point estimates of potential growth at the end of the sample range from 2.3 to 2.4 , whereas the point estimates of the output gap range from -0.3 to -0.9. Importantly, these differences are modest when considered in the context of the uncertainty surrounding point estimates of potential output and the output gap (Appendix B). 